\title{
Seasonal and Inter-annual Variations of Lake Surface Area of Orog Lake in Gobi, Mongolia During 2000-2010
}

\author{
Heejae Yang, Eunhye Lee, Nayoung Do, Dongwook Ko and Sinkyu Kang ${ }^{\dagger}$ \\ Department of Environmental Science, Kangwon National University
}

\begin{abstract}
Terminal lakes are widely distributed in the arid and semi-arid Gobi of Mongolia, and serves as important water resource for local people and livestock. However, such lakes are subject to great fluctuations in its size depending on climatic conditions and human water utilization. The Orog Lake is one such example that has shown remarkable fluctuation in recent years. In this study, we investigated the temporal changes of Orog Lake surface area by using 16-day MODIS $250 \mathrm{~m}$ NDVI products from 2000 to 2010. The results were compared with climate variability represented by monthly precipitation and temperature. Our results show that the Orog Lake gradually shrank for the period from 2000 to 2010, but with a significant range of seasonal and inter-annual variability. The lake area showed considerable seasonal variations, as it expanded in spring and fall, primarily due to snow melt and summer precipitation, respectively. Extreme drought period from 2000 to 2002 triggered the substantial reduction in lake area, leading to dry-up in year 2005, 2006, 2007, and 2009. After dry-up once occurred in 2005, the lake repeated reappearance and disappearance depending on seasonal and annual precipitation. Our findings implicate that the ground water fluctuated around the lake bottom level since 2005. This suggests the highly vulnerable nature of Orog lake, which greatly depends on future precipitation change.
\end{abstract}

Key Words : lake area change, MODIS NDVI, precipitation

\section{Introduction}

Mongolia is a land-locked country, mainly comprised of arid and semi-arid environment with limited water resource. Arid and semi-arid regions of Mongolia are experiencing land degradation according to UNCCD guideline for desertification (UNEP RRC.AP, 2002). In particular, Mongolia's grasslands showed various symptoms of land degradation in the last 60 years, and various studies suggest that it might be related to changes in regional climate (Natsagdorj et al., 2003; Kim, 2008; Lee and Sohn, 2011) and socio-economic situation (Dietz et al., 2005; Johnson et al., 2006). Batima et al. (2005) reported Mongolia experienced an increase in annual mean temperature by $1.6^{\circ} \mathrm{C}$ and a decrease in winter and spring precipitation since the 1960s. Such changes can exert regional water balance of grassland ecosystems leading to reduced water resource in Mongolia.

\footnotetext{
Received December 22, 2011; Revised March 5, 2012, Revised April 14, 2012; Accepted April 15, 2012.

${ }^{\dagger}$ Corresponding Author: Sinkyu Kang (kangsk@kangwon.ac.kr)
} 
In 2004, Mongolian government published a comprehensive report revealing that 683 streams and rivers, 1484 wells and springs, and 760 lakes have disappeared between late 1990s and early 2000s (Davaa, 2007). This is an alarming phenomenon considering the limited water resource of Mongolia, which is extremely important to preserve the sustainability of ecosystem functions and livelihood of local inhabitants. It is hence imperative to monitor the dynamics of water resources and to understand the primary driving forces on the water resource variability, which can provide scientific grounds on developing effective strategies for water resources management in the Mongolian dryland ecosystem. In particular, lake are of great interest as it is undoubtly the largest water resource $\left(500 \mathrm{~km}^{3} \mathrm{yr}^{-1}\right)$ in Mongolia, followed by $34.6 \mathrm{~km}^{3} \mathrm{yr}^{-1}$ by rivers, $62.9 \mathrm{~km}^{3} \mathrm{yr}^{-1}$ by glaciers, and $12 \mathrm{~km}^{3} \mathrm{yr}^{-1}$ by groundwater (Davaa, 2007).

Remote sensing is an effective approach for monitoring changes in land surface water resources over large areas such as Mongolia. Several studies have been conducted to investigate a variety of aspects of changes in lake properties in the dryland regions of Asia. Nakayama et al. (2007) utilized multiple satellite data including Landsat, ASTER, MODIS, NOAA AVHRR, and JERS-1, to evaluate long-term change of lake area in the Central Asia. They reported rapid shrinkage of closed lakes in Dzungar Basin of the Central Asia in the past 50 years, which again rapidly expanded since 2002 . They interpreted that the changes were more closely associated with human activity such as irrigated agriculture rather than natural fluctuation based on the climate change. Komatsu et al. (2001) conducted research on Orog Lake located in southern Mongolia using RADARSAT SAR imageries. They reported that Orog Lake has greatly expanded during the periods of Pleistocene and Holocene, resulting in increased human demography in this area. Chuluun et al. (2010) reported that the surface area of Orog lake has been widely fluctuating since the early 2000 s, including a complete dry-up, albeit temporary, in 2009, which brought strong negative effects on local economy in the lower basin area.

Since late 1990s, two major zud events (i.e. massive kills of livestock due to harsh winter condition) occurred in the dry regions in Mongolia. In particular, the 3-year zud event from late 1999 to early 2002 was recorded as one of most severe zud disasters in the last several decades: this event alone resulted in 30\% reduction in livestock population in Mongolia (Saizen et al., 2010). Zud events are directly associated with harsh winter condition, such as severely cold weather, heavy snow, or formation of surface ice cover preventing livestock from grazing. However, zud conditions can be exacerbated by severe drought condition in the previous growing season, as it will reduce grass biomass available for livestock grazing resulting in weakened livestock vitality, and reduced winter forage (Robinson and Milner-Gulland, 2003; Saizen et al., 2010). In addition, such drought condition can also shrink lake surface area by drawing down ground water level, which resulted in dry-up of wells that primarily provided drinking water for livestock in dry and semi-dry regions in Mongolia. Increase in dry wells often result in localized over-grazing activities around remaining wells, leading to increased risk of grassland ecosystem degradation (Chuluun et al., 2010).

Hence, detection of lake area decrease can provide important information on seasonal or inter-annual imbalance of water budget resulting in reduced productivity and degradation of grassland, and the potential hazard from zud event in the following winter season. For this purpose, the satellite data utilized for the lake surface detection should have the 
capability to capture seasonal dynamics of even small-sized lakes that are widely distributed in dry regions. On the ground, MODIS (Moderate Resolution Image Spectroradiometer) 250 m NDVI (Normalized Differenced Vegetation Index) product is one of the preferred dataset because it has 16-day temporal period to assure detection of seasonal variation of lake size with relatively high spatial resolution, compared to NOAA AVHRR and MODIS $1 \mathrm{~km}$ products. In previous studies, the MODIS $250 \mathrm{~m}$ NDVI product was successfully applied to detect flood (Brakenridge and Anderson, 2005) and to estimate lake area (Peng et al., 2005). Therefore, this dataset may have the potential for rapid detection of lake area change for the purpose of early warning on potential hazards, such as zud event and desertification, which needs to be evaluated.

In this study, we applied the MODIS 250 m NDVI product to examine seasonal and inter-annual variation of the Orog lake in Mongolian Gobi region. Using the results, we interpreted the lake area dynamics in relation with seasonal and inter-annual variations of temperature and precipitation in the basin scale. Finally, we discussed limitations of this study and future research directions, how to improve the reliability of lake area detection and ways to apply this method to understand regional water budget and also to diagnose socio-ecological vulnerability in the lake basin.

\section{Materials and methods}

\section{1) Study area}

The Orog lake $\left(45^{\circ} 01^{\prime} \mathrm{N} 100 \mathrm{o} 22^{\prime} \mathrm{E}\right)$ is a terminal lake located in the southern end of Tuin river basin (Fig. 1). Tuin river originates from the Khanggai Mountain Range in central Mongolia. The lake is

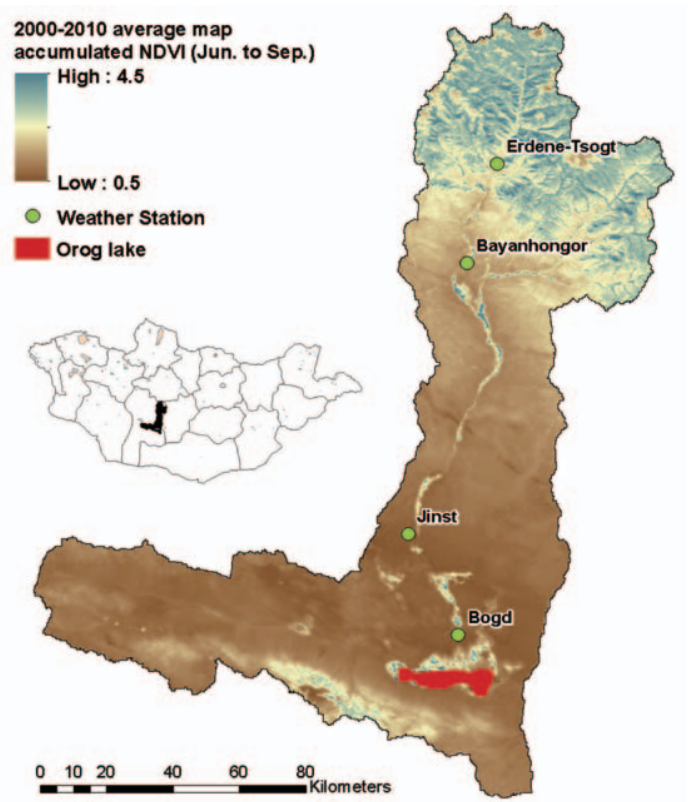

Fig. 1. Locations of Orog Lake basin and weather stations (dots). The base map is June-September NDVI accumulation averaged from 2000 to 2010.

located within the Bogd sum of Arhanggai aimag with an elevation of 1,210-1,220 m (Komatsu et al., 2001; Krylov et al., 2011). Tuin river is the primary water source to the lake. It was reported that the river discharge has decreased with considerable fluctuations since early 2000s (Chuluun et al., 2010).

From north to south, precipitation decreases but temperature increases in Tuin river basin. Accordingly, biome types vary from forest steppe, steppe, and desert steppe. Mean annual precipitation during 2000s was $186 \mathrm{~mm} \mathrm{y}^{-1}$ and $77 \mathrm{~mm} \mathrm{y}^{-1}$ in Erdenetsogt and Jinst, respectively (Fig. 1). Pastoral animal husbandry is a major economic activity in the basin. It is known there is no mining activity in the basin (Chuluun et al., 2010). Bayanhongor city located in the northern part of the basin (Fig. 1) is the biggest residential and commercial area with population of 25,000 . 


\section{2) Data collection and manipulation}

\section{(1) MODIS data}

MODIS NDVI is one of level-3 MODIS Land Product dataset that are generated from MOD09 Land Surface Reflectance data (Huete et al., 2002). The NDVI is produced at 4 different resolutions (i.e. 250 $\mathrm{m}, 500 \mathrm{~m}, 1 \mathrm{~km}$, and 0.05 degree) and in 2 projections (Sinusoidal and Geographic). Except for 0.05 degree NDVI, another NDVI datasets are produced in Sinusoidal (SIN) production. In order to maintain reasonable accessible file sizes, the SIN projection is divided up into a tiled grid that is composed of adjacent non-overlapping tiles with their predefined geo-locations. The tiled grid has number of tiles of 36 horizontal (i.e. longitudinal) and 18 vertical (i.e. latitudinal) segmentations. Each $250 \mathrm{~m}$ NDVI tile has $4800 \times 4800$ pixels with approximate area of 10 degrees square at the equator.

In this study, Terra MOD13Q1 250 m 16-day NDVI data were collected from National Aeronautics and Space Administration (NASA) WIST download service system. The Tuin river basin is located within a 25th horizontal and 4th vertical MODIS NDVI tile in the tiled grid. We acquired total 253 number of NDVI tile data from 2000 to 2010. We used IDL/ ENVI software (RSI Inc.) to convert the projection of the images from SIN to UTM zone 48 North and subsequently extracted subset images of the Tuin river basin (Fig. 1). The basin boundary was extracted from a Mongolia watershed boundary map provided by World Wildlife Foundation.

\section{(2) Meteorological data}

Meteorological data was acquired from national meteorological monitoring sites of Mongolia located within the Tuin river basin, which include meteorological stations at 4 sums in the Arhanggai aimag: Erden-Tsogtsum, Bayanhongor, Jinst, and
Bogd sums (Fig. 1). We collected monthly precipitation and monthly mean temperature from 1990 to 2010. To consider the effect of snowfall on the lake area, we assumed that precipitation in months with mean temperature lower than $-5^{\circ} \mathrm{C}$ as snow, and examined the relationship of snowfall in the previous winter season with the lake area in the following spring. We also calculated annual cumulative precipitation to consider the annual precipitation effect on inter-annual lake area variations.

\section{3) Lake area detection and change analysis}

While NDVI value ranges between -1 to +1 , the index is also characterized by sensitive response to water bodies, generally represented by negative or very low positive value, which indicates the presence of surface, snow, or highly saturated soil conditions. While negative NDVI is generally considered to represent water bodies, high level of water sediment or salt concentration can increase near-infrared reflectance, leading to positive NDVI values (Jensen, 2005). Considering the potentially high sediment concentration of the shallow Orog lake (Chuluun et al., 2010), we decided to use threshold NDVI value of 0.03 for lake area classification. The threshold value of 0.03 was empirically identified by visual interpretation in ArcGIS software at a value showing the largest distinct lake shape for the data period (2000-2010). Any pixel with NDVI value lower than the threshold was classified as lake water. One source of uncertainty is the presence of snow and ice during winter and early spring, which generally shows negative NDVI value. To avoid this problem, we only used the NDVI images from late spring to early autumn (i.e. days of year, DOY, from 145 to 273) for the lake area detection.

We analyzed the annual trend of variability in the lake area by calculating annual mean, maximum and 
minimum lake areas from 2000 to 2010 , and compared them with annual cumulative precipitation and annual mean temperature. We also compared wintertime snowfall with springtime lake area to examine whether water input from snow melt provides enough recharging water or not.

\section{Results and discussions}

Seasonal and inter-annual variations of lake area from DOY 145 to 273 for the years of 2000-2010 are illustrated in Fig. 2. The Orog lake showed considerable seasonal and inter-annual variations of lake area for the study period. The variability can be characterized with several stages. The first stage from 2000 to mid 2002 showed relatively stable lake area. During the second stage from mid 2002 to 2004 , lake water was detected year-round but to a limited extent. The third is from 2005 to 2010 in which the lake disappeared and reappeared repeatedly.

Time series of the lake area showed distinct decreasing pattern since 2000 (Fig. 3). In spite of considerable seasonal fluctuations, the lake area consistently decreased from 2000 to 2010 . Seasonal variations were generally characterized by lake area decreasing in spring and then increasing after summer rainy season (Fig. 3a). However, such seasonal patterns were not found in years 2001, 2002, and 2009. Springtime lake area was well correlated with the wintertime snowfall $(r=0.68, p<0.05)$ except for years 2000 and 2001. However, high snowfall in 2006-2007 winter seasons could not help the almost completely dry lake to recover in the following spring. In contrast, we could not find any meaningful relationship between the lake area and air temperature

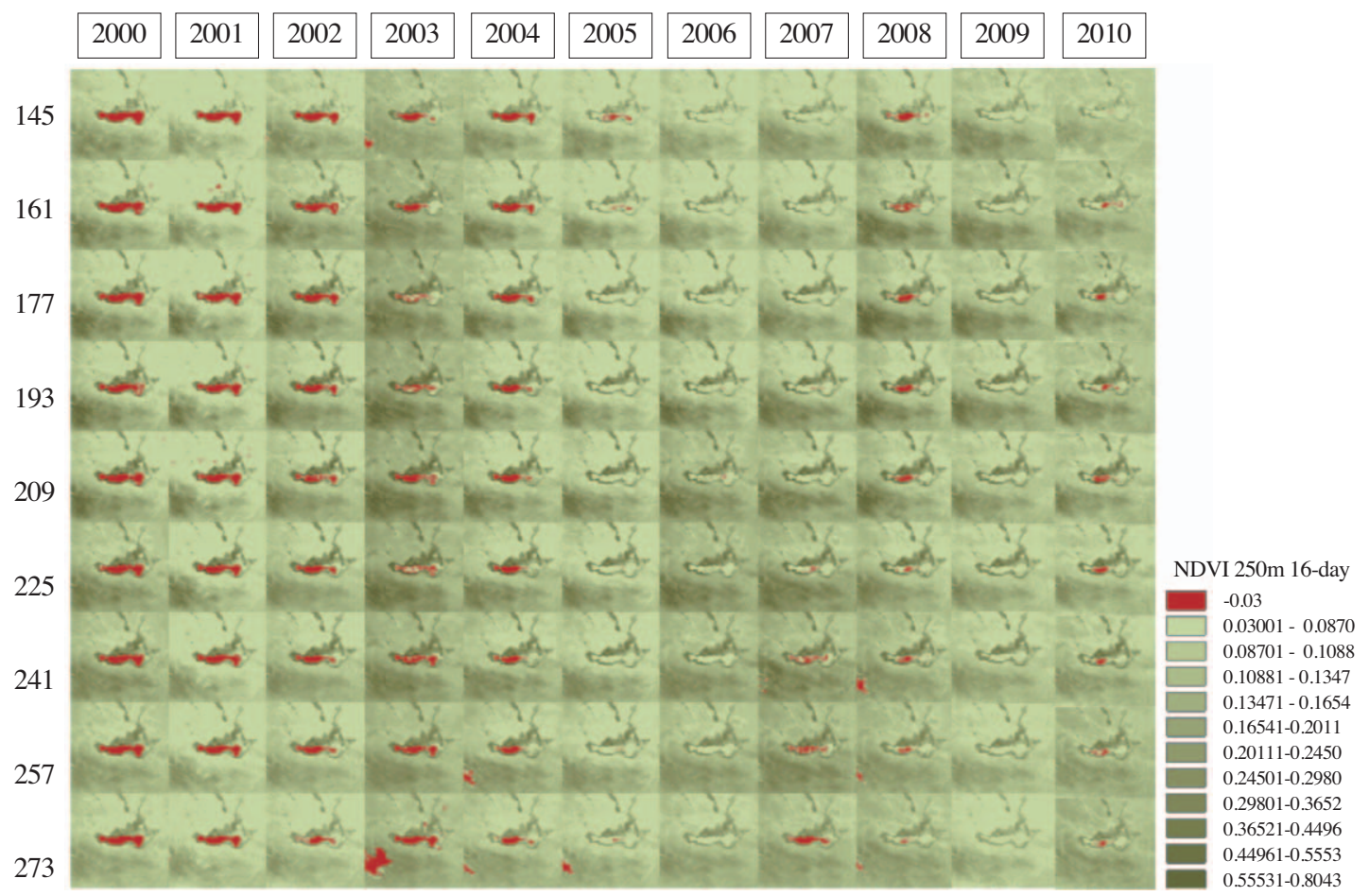

Fig. 2. Subset images of MODIS $250 \mathrm{~m}$ NDVI on the Orog Lake for DOY 145-273 from 2000 to 2010 . The red color is area identified as lake water. In some image, snow was also identified as red color but was discarded in counting number of lake water pixels. 


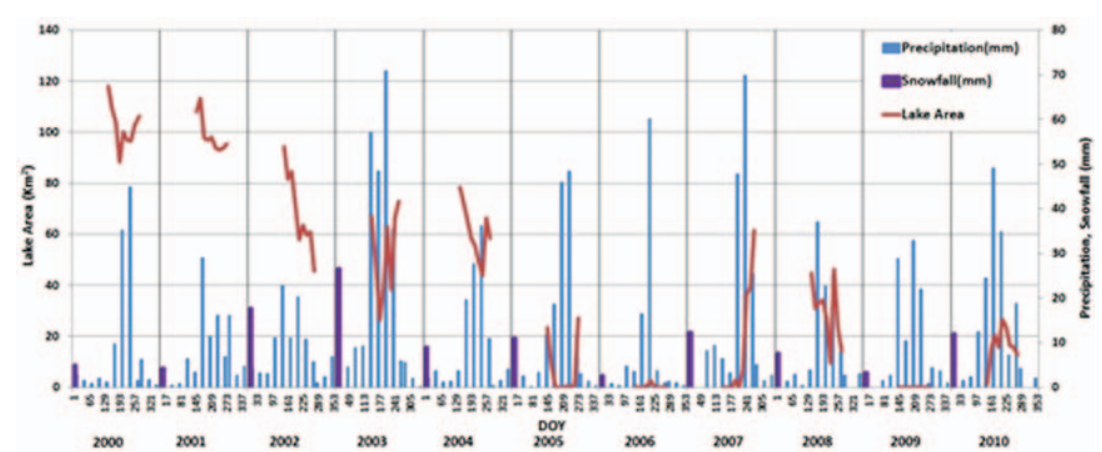

(a)

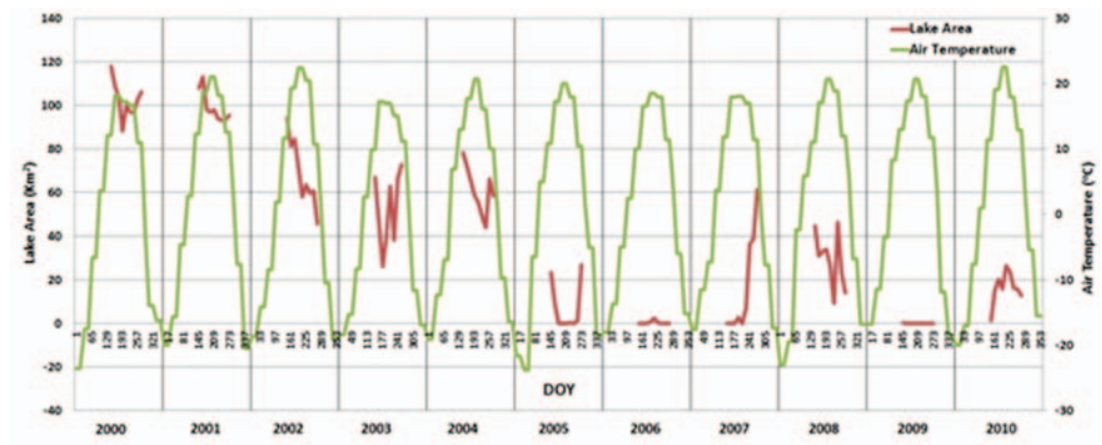

(b)

Fig. 3. Time series of (a) monthly precipitation $\left(\mathrm{mm} \mathrm{mon}^{-1}\right)$ and winter snow fall $(\mathrm{mm})$ and (b) monthly temperature $\left({ }^{\circ} \mathrm{C}\right)$ from 2000 to 2010. The lake area $\left(\mathrm{km}^{2}\right)$ was overlayed in each figure.

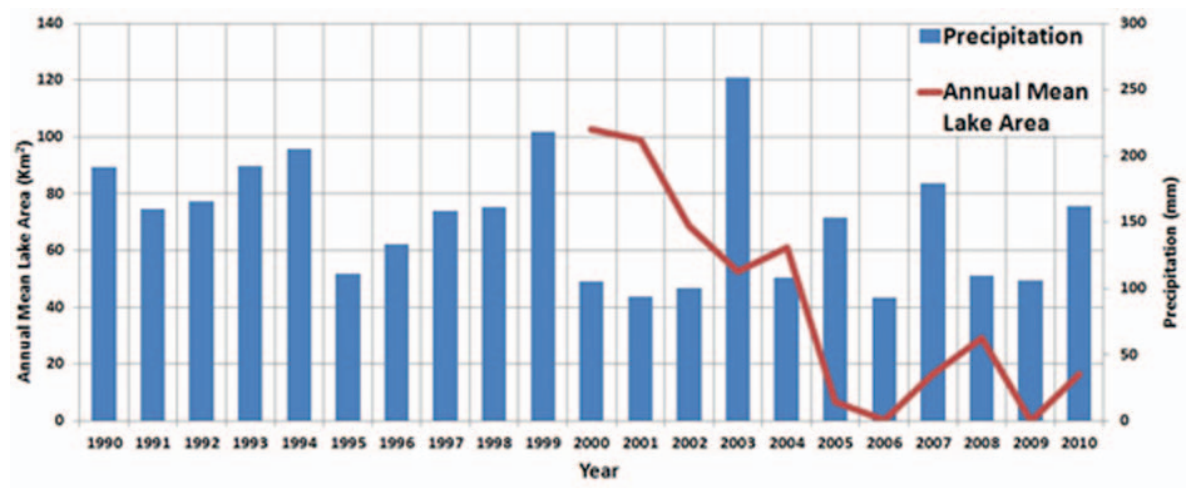

Fig. 4. Time series of annual precipitation ( $\mathrm{mm} \mathrm{yr}^{-1}$ ) for 1990-2010 and annual mean lake area $\left(\mathrm{km}^{2}\right)$ for 2000-2010.

(Fig. 3b).

The large lake area in early 2000s seems to be related to high precipitation during 1990 s, while the decreasing lake area in 2000 s was due to decreased precipitation in the corresponding period (Fig. 4). Mean annual precipitation (MAP) was $170 \mathrm{~mm} \mathrm{yr}^{-1}$ during 1990s but decreased by 23\% during 2000s (131 $\left.\mathrm{mm} \mathrm{yr}^{-1}\right)$. In particular, the MAP during 20002002 was $102 \mathrm{~mm} \mathrm{yr}^{-1}$, which was only $60 \%$ of the 1990s MAP. This extremely dry period in early 2000s seems to trigger considerable reduction of lake area in 2002. The decreasing trend of the lake area 
briefly slowed down during 2003-2004 likely due to the high precipitation in 2003 , but was not enough to recover the lake area. Subsequently, the lake area shrank again in the following dry years and repeated temporary dry-up and reappearing thereafter.

Correlation analysis showed limited relationships between lake area and meteorological variables. Annual mean lake area showed insignificant correlations with annual precipitation $(r=+0.04)$ and annual mean temperature $(\mathrm{r}=+0.10)$. In contrast, the winter snowfall was well related with spring lake area $(r=+0.48$ for the entire study period, $r=+0.68$ with the exclusion of 2000 and 2001). It is rather surprising to find weak correlation between inter-annual lake area and precipitation variations, although we did find some relevance between precipitation seasonality and seasonal lake area variation.

For terminal lakes, lake area is primarily determined by ground water level that is controlled by basin-scale land surface water budget through precipitation, snow melt, evapotranspiration, soil water storage change, and anthropogenic water use. Hence, lake area detected from satellite data may actually represent the condition of basin-scale ground water change. The seasonal lake area variation found in this study indicates that the ground water level responded well to seasonal patterns of precipitation and snow melt in a temporal scale of a few months. The lake dry-ups in years 2005, 2006, 2007, and 2009 imply that the ground water level may have drawn down to below lake bottom. Our results indicate that since 2005, the ground water level fluctuated around the lake bottom level showing temporary lake recovery in 2007-2008 and 2010 due to increased precipitation in 2007 and 2010. Otherwise the lake would have completely disappeared like Ulaan Lake, which was once the largest lake in Gobi area (Chuluun et al., 2010).

On the other hand, our results show the indeterminate role of increasing temperature for the last several decades (Batima et al., 2005) in determining the ground water level of the Tuin river basin. In long-term perspective, increased temperature can exert both negative and positive effects on the lake area by increasing water loss through evapotranspiration (Li et al., 2006) and by enhancing water input through permafrost melting that is widely distributed in the northern part of Tuin river basin (Ishikawa et al., 2005). Rapid increase of livestock populations triggered by livestock privatization since 1992 (Johnson et al., 2006) could be also an important concern of understanding regional water balance. It is however uncertain whether increased water use by livestock exerts significant effect on ground water change. On the contrary, it was reported that number of wells dried up with recent ground water reduction in Mongolia (Daava, 2007), which enhanced land degradation vulnerability by intensifying livestock grazing around remaining wells (Neupert, 1999; Johnson et al., 2006). In this study, we could not address the abovementioned questions about the roles of increasing temperature and livestock populations on ground water change and about the feedback process between livestock and ground water dynamics. In a future study, newly developed remote sensing techniques could be applied for reliable estimation of land surface evapotranspiration using MODIS data (Jang et al., 2010; Ryu et al., 2011) and livestock inventory data from Mongolian government (Saizen et al., 2010) could be utilized to estimate livestock water use to account for the effects of increased temperature and livestock populations.

There are at least two technical limits worth discussion in our study. Firstly, we utilized an empirical threshold NDVI of 0.03 to detect lake water. The value was identified by visual interpretation when the lake area was the largest with 
distinct lake boundary during 2000 and 2001. Hence, the lake water detected in this study should be regarded as an approximation, representing the lake marginal area with respect to the maximum lake area. Secondly, our utilization of the lake area as a surrogate of basin-scale ground water depth was not evaluated with field observations. Rather than lake area, lake depth may be more directly related to ground water level. Since the relation between lake area and depth is highly dependent on lake morphology, one must be cautious when linking lake area variability with land surface water budget, especially without priory information on lake morphology.

\section{Conclusions}

Our results show that the Orog lake gradually shrank for the period from 2000 to 2010, but with a remarkable range of seasonal variability. The lake area showed considerable seasonal variations, with larger area in spring and fall, primarily due to snow melt and summer precipitation, respectively. Extreme drought period from 2000 to 2002 triggered the substantial reduction in lake area, leading to dry-up in year 2005, 2006, 2007, and 2009. After once dry-up in 2005, the lake repeated reappearance and disappearance depending on seasonal and annual precipitation. Our findings imply that the ground water fluctuated around the lake bottom level since 2005, which means the fate of Orog lake is highly vulnerable and depends on favorable future precipitation condition.

Our findings also suggest a significant time-lag in the response of lake area to extreme drought events in early 2000s, leading to a conclusion that short-term meteorological data alone is not a sufficient explanatory variable to explain patterns and mechanisms of lake area change. Better explanation on lake area dynamics may be attainable by considering other various hydrological processes including evapotranspiration and permafrost melting and anthropogenic water use (i.e. livestock or mining activity).

\section{Acknowledgement}

This study is supported by Kangwon National University. The authors greatly appreciate Chuluun, Chunt, and Altanbagana in providing the climate data used in this study.

\section{References}

Batima, P., L. Natsagdorj, P. Gombluudev, and B. Erdenetsetseg, 2005. Observed climate change in Mongolia, AIACC Working Paper (http://www.aiaccproject.org), 13, 5-20.

Brakenridge, R. and E. Anderson, 2005. MODISbased flood detection, mapping and measurement: the potential for operational hydrological applications, Edited by J. Marasalek, G. Stancalie, G. Balint, in Transboundary floods: reducing risks through flood management, Earth and Environmental Sciences, 72: 1-12.

Chuluun, T., M. Altanbagana, and B. Tserenchunt, 2010. Land Degradation and Desertification in Mongolia, Background paper for Mongolian Human Development Report, Ulaanbaatar, Mongolia.

Davaa, G., 2007. Surface Water of Mongolia, Annual report for Institute of Meteorology and Hydrology, Ulaanbaatar, Mongolia.

Dietz, A.J., E. Amgalan, T. Erdenechuluun, and S. 
Hess, 2005. Carrying capacity dynamics, livestock commercialisation and land degradation in Mongolia's free market era. PREM Working Paper, 1-15.

Huete, A., K. Didan, T. Miura, E.P. Rodriguez, X. Gao, and L.G. Ferreira, 2002. Overview of the radiometric and biophysical performance of the MODIS vegetation indices, Remote Sensing of Environment, 83: 195-213.

Ishikawa, M., N. Sharkhuu, Y. Zhang, T. Kadota, and T. Ohata, 2005. Ground thermal and moisture conditions at the southern boundary of discontinuous permafrost, Mongolia, Permafrost and Periglacial Processess, 16: 209-216.

Jang, K., S. Kang, J. Kim, C.B. Lee, T. Kim, J. Kim, R. Hirata, and N. Saigusa, 2010. Mapping evaporanspiration using MODIS and MM5 Four-Dimensional Data Assimilation, Remote Sensing of Environment, 114: 657-673.

Jensen, J.R., 2005. Introductory Digital Image Processing, 3rd Edition, Prentice Hall.

Johnson, D.A., D.P. Sheehy, D. Miller, and D. Damiran, 2006. Mongolian rangelands in transition, Secheresse, 17: 133-141.

Kim, J., 2008. Transport routes and source regions of Asian dust obsered in Korea during the past 40 years (1965-2004), Atmospheric Environment, 42: 4778-4789.

Komatsu, G., P.J. Brantingham, J.W. Olsen, and V.R. Baker, 2001. Paleoshoreline geomorphology of Boon Tsagaan Nuur, Tsagaan Nuur and Orog Nuur: the Valley of Lakes, Mongolia, Geomorphology, 39: 83-98.

Krylov, A.V., B. Mendsaikhan, and B. Gantstsooz, 2011. Zooplankton of the drying Lake Orog (Mongolia), Inland Water Biology, 4: 179181.

Lee, E.H. and B.J. Sohn, 2011. Recent increasing trend in dust frequency over Mongolia and Inner Mongolia regions and its association with climate and surface condition change, Atmospheric Environment, 45: 4611-4616.

Li, S.G., W. Eugster, J. Asanuma, A. Korani, G. Davaa, D. Oyunbaatar, and M. Sugita, 2006. Energy partitioning and its biophysical controls above a graing steppe in central Mongolia, Agricultural and Forest Meteorology, 137: 89-106.

Nakayama, Y., T. Yanagi, S. Yamaguchi, J. Nishimura, and G. Mu, 2007. Monitoring of environmental change in Dzungar Basin by the analysis of multi-temporal satellite data sets, Advances in Space Research, 39: 52-59.

Natsagdorj, L., D. Jugder, and Y.S. Chung, 2003. Analysis of dust storms observed in Mongolia during 1937-1999, Atmospheric Environment, 37: 1401-1411.

Neupert, R.F., 1996. Population, nomadic pastoralism and the environment in the Mongolian Plateau, Population and Environment, 20: 413-441.

Peng, D., L. Siong, S. Guo, and N. Shu, 2005. Study of Dongting Lake area variation and its influence on water level using MODIS data, Hydrological Sciences Journal, 50: 31-44.

Robinson, S., and E.J. Milner-Gulland, 2003. Political change and factors limiting numbers of wild and domestic ungulates in Kazakhstan, Human Ecology, 31: 87-110.

Saizen, I., A. Maekawa, and N. Yamamura, 2010. Spatial analysis of time-series changes in livestock distribution by detection of local spatial associations in Mongolia, Applied Geography, 30: 639-649.

Ryu, Y., D.D. Baldocchi, H. Kobayashi, C. van Ingen, J. Li, T.A. Black, J. Beringer, E. van Gorsel, A. Knohl, B.E. Law, and O. Roupsard, 2011. Integrating of MODIS land and 
atmosphere products with a coupled-process model to estimate gross primary productivity and evapotranspiration from $1 \mathrm{~km}$ to glbal scales, Global Biogeochemical Cycles, 25, GB4017.
UNEP RRC.AP, 2002. State of environment, Mongolia 2002. AIT-UNEP Regional Resource Centre for Asia and Pacific (RRC.AP), http://www.rrcap.unep.org/pub/ soe/mongoliasoe.cfm. 